\title{
ROLE OF INTERMITTENT SELF DILATATION IN THE PREVENTION OF URETHRAL STRICTURE RECURRENCE AFTER DIRECT VISUAL INTERNAL URETHROTOMY: A RANDOMIZED CONTROLLED TRIAL
}

\author{
S. K. Singh ${ }^{1}$, C. S. Agrawal ${ }^{1}$, S Agrawal ${ }^{2}$, N Thapa ${ }^{1}$, R. S. Shah ${ }^{1}$ \\ ${ }^{1}$ Department of Surgery, B. P. Koirala Institute of Health Sciences, Dharan, Nepal \\ ${ }^{2}$ Department of dermatology and venerology, B.P. Koirala Institute of Health Sciences, Dharan, Nepal
}

\begin{abstract}
Urethral stricture refers to scarring process involving corpus spongiosum. Strictures may be from: prostatectomy, perineal trauma, urethral catheterization, idiopathic/unknown, urethritis, and cystoscopy. Direct visual internal urethrotomy followed by intermittent self-dilatation is the most commonly performed intervention for urethral stricture. The aim of current study is to compare the efficacy of Direct Visual Internal Urethrotomy followed by Intermittent Self Dilatation versus No Dilatation. A total of 15 patients in each group were included. Groups were the subjects with urethral stricture with no dilatation and with intermittent selfdilatation. Retrograde urethrogram and micturating cystourethrogram were performed to evaluate the site and size of Stricture. Uroflowmetry was performed before the start of treatment to record the maximum flow rate. On the result of urethrocystoscopy (free passage of the 20F scope to the bladder) a diagnosis of recurrence was determined. Group comparison of efficacy was assessed by chi square test and Mann Whitney U test. The IPSS scores were $25.27 \pm 5.57$ in intervention group and $22.53 \pm 5.35$ in control group. Uroflowmetry score was 6.20 \pm 1.89 in intervention group and $5.73 \pm 1.94$ in control group. Stricture size was $9.67 \pm 3.65 \mathrm{~mm}$ in intervention group and $8.47 \pm 4.56 \mathrm{~mm}$ in control group. Analyzing the stricture at 6 months, in the intervention group $(n=15)$, none had stricture whereas in control group, 3 out of 14 had stricture. Analyzing the stricture at 6 months per Intention to treat, in the intervention group $(n=15)$, none had stricture whereas in control group, 3 out of $15(20 \%)$ had stricture. Thus the study showed that recurrence of stricture was markedly decreased over the six month of follow up period in the intermittent self-dilatation group.
\end{abstract}

Keywords: Direct Visual Internal Urethrotomy, micturating cystourethrogram, urethral strictures, intermittent self-dilatation, Uroflowmetry

\section{INTRODUCTION}

Urethral stricture refers to anterior urethral disease, a scarring process involving the spongy erectile tissue of the corpus spongiosum, also referred to as spongiofibrosis $^{1}$. $80 \%$ of strictures that are secondary to instrumentation occur at the membranous urethra. The other $20 \%$ generally occur at the penoscrotal junction. A study done by Palminteri et al 2 on 1439 patients with urethral stricture showed that 675 patients (46.9\%) had stricture in the bulbar urethra and very few had penile plus bulbar urethral stricture.

Before the $21^{\text {st }}$ century, the majority of urethral strictures resulted from urethritis or sexually transmitted diseases. Post inflammatory strictures are seldom seen in todays developed world. Instead, urethral strictures may be from: prostatectomy, perineal trauma, urethral catheterization, idiopathic/unknown, TUR, hypospadias, pelvic fracture, urethritis, cystoscopy and lichen sclerosis ${ }^{3}$.

Email: drsinghsudhir@gmail.com

http://dx.doi.org/10.20530/IJTA_33_110-118

ISSN 2320-138X @ 2016
Kashefi et $a l^{4}$ demonstrated that an estimated 3.2 urethral injures per 1000 inpatients were secondary to traumatic catheterizations. Stein et $\mathrm{al}^{5}$ in retrospective study involving 2589 patients showed that the most common cause for stricture was idiopathic at $41.3 \%$ followed by iatrogenic at $35 \%$. In the other study done by Stein et $\mathrm{al}^{5}$ in India the most common cause was traumatic at $36 \%$. In patients younger than age 45, hypospadias surgery, idiopathic, lichen sclerosis and pelvic fracture are among the most common causes of urethral strictures. $^{3}$

Urethral stricture remains complicated surgical problem for mankind since ancient time and thus the treatment remains to evolve. In the history, the earliest recorded attempt to treat the stricture was metal dilator. Later on it was replaced by blind internal urethrotome by Civiale and Ottis in $18^{\text {th }}$ century but had not gained much popularity because of their complications and poor result. Since then, the practice of dilatation has not changed significantly. DVIU was popularized after the initial report of Sachse in 1972. In the 1980s, the concept of intermittent self-dilatation (ISD) following DVIU took shape in order to decrease stricture recurrence. 
Urethral stricture is still unsolved problem because of its recurrence. Dilatation, Direct Visual Internal Urethrotomy (DVIU) by cold knife, Holmium laser urethrotomy, urethral stents and urethroplasty are the modalities used to restore the continuity of the urethra. Holmium laser is the upcoming treatment modality. In the recently published meta-analysis the success rate of patients treated with laser was $74.9 \%$ compared with $68.5 \%$ for cold knife, with very similar clinical results. Direct visual internal urethrotomy (DVIU) followed by intermittent self-dilatation (ISD) is the most commonly performed intervention for urethral stricture disease. This approach is appealing both for urologists and the patients as it is minimally invasive. DVIU is best utilized for short strictures less than $1.5 \mathrm{~cm}$ that involves the bulbar or pendulous urethra. ${ }^{6}$ DVIU has a long term success rate of $74 \%$ if the above criteria are met. DVIU success can be improved if urethral dilation is performed greater than 1 year $(80 \%){ }^{1}$

There are many case series of DVIU with ISD but there are only three randomized controlled trials (RCT) uptill now comparing DVIU with ISD and without ISD. The results of these studies, Kjaeergard et $\mathrm{al}^{6}$, Bodker et $\mathrm{al}^{7}$ and Matanhelia et $\mathrm{al}^{8}$ are conflicting. Bodker et $\mathrm{al}^{7}$ and Matanhelia et $\mathrm{al}^{8}$ stated no difference in outcome between patients with ISD and without ISD in their study whereas Kjaeergard et al $^{6}$ showed significant difference between the two groups $19 \%$ and $68 \%$ respectively.

Nepal is geographically varied country. Patients come from distant places; have difficulty to come for follow up. There is no RCT done in this sub-continent as per our literature search. Therefore, a prospective, assessor blinded, parallel group, randomized controlled trial was undertaken to compare the efficacy of intermittent self-dilatation versus no dilatation following DVIU.

This study may help us in further planning of treatment strategy in urethral stricture. This study will further support the current scientific evidence for the use of ISD after DVIU in the management of anterior urethral strictures. The aim of current study is to compare the efficacy of Direct Visual Internal Urethrotomy followed by Intermittent Self Dilatation versus No Dilatation. Evaluating rate of urethral stricture recurrence within 6 month will access the efficacy.

\section{MATERIAL AND METHODS}

Study Subject and Design

A total of 15 patients in each group were included. Groups were the subjects with recurrence of urethral stricture with no dilatation and with intermittent selfdilatation. The subjects were the consecutive patients with urethral stricture attending or referring to the Out Patient Department of Surgery or Urology at B.P. Koirala Institute of Health Sciences, Dharan within the duration of $1^{\text {st }}$ July $2014-30^{\text {th }}$ June 2015 . This study is the two-arm, parallel design, assessor blinded; randomized controlled trial where purposive sampling technique (consecutive patients) was used for sample collection. Ethical clearance was taken from the Institutional Ethical review Board of the BP Koirala institute of health sciences (IERB).

\section{Inclusion Criteria}

Patients who were treated with Direct Visual Internal Urethrotomy for stricture localized to the bulbar and pendulous urethra of less than $1.5 \mathrm{~cm}$ of stricture length as on imaging (Retrograde Urethrography) were included in the study.

\section{Exclusion Criteria}

1. Long segment strictures

2. Patient not willing to give consent

3. Previous history of intervention

4. Cancer of the prostate

5. Tumors of the bladder requiring check cystoscopies

6. An inability to learn or perform Intermittent Self Dilatation for any reason

\section{Randomization and Allocation Concealment}

The randomization schedule were developed using random permuted blocks (size $4 \& 6$ ) in a ratio 1:1 ratio with the help of web based program of www.randomisation.com. The patients were assigned randomly to either Intermittent Self Dilatation group (treatment group) or No Self Dilatation (control group) by means of a sequentially numbered envelope in which the allocation were indicated. The sealed envelopes were numbered from 1 to 30 and opened in ascending order.

\section{Blinding}

Due to nature of the procedure only the assessor was blinded.

\section{Methodology}

All consecutive patients with urethral stricture attending or referring to the Out Patient Department of Surgery or Urology at B.P. Koirala Institute of Health Sciences, Dharan were studied. A detailed history about the causation of the stricture and lower urinary tract symptoms (as per AUA guideline) was recorded.

In addition to history, clinical examination and routine laboratory investigations, radiological evaluation including retrograde urethrogram (RGU) and micturating cystourethrogram (MCU) were 
performed to evaluate the site and size of the Urethral Stricture. Uroflowmetry was performed in all patients before the start of treatment to record the maximum flow rate. Urinary tract infections (UTI) were treated in all patients according to urine culture sensitivity before performing DVIU. Those fulfilling the inclusion and exclusion criteria were provided with the printed information in Nepali/English. This information sheet informed them about the nature of urethral stricture, the difficulty in treatment and the problem of recurrence. The method of ISD was explained to the patient and relatives in detail with diagrammatic sketch.

Those patients agreeing were requested to sign consent form and then were randomly allocated into one of the two treatment groups after they understood the nature of the study, a state of dilemma and state of equipoise. The patients were allotted into intermittent self dilatation (Group ) or no dilatation (Group II: without ISD) with follow up for 6 months.

\section{DVIU Procedure}

A standard Direct Visual Internal Urethrotomy Procedure was performed with the patient in lithotomy position under spinal anesthesia. All the procedures were carried out by single surgeon to avoid the operative technique bias. At operation, the stricture was incised at 12 O'clock under direct vision, using a Storz Optical Urethrotome incorporating a Sachse knife. An indwelling Foley catheter, $16 \mathrm{Fr}$, was inserted in each patient following surgery, and remained in position for 4 days.

\section{Intervention}

ARM-I: INTERMITTENT SELF DILATATION GROUP

After removal of the indwelling catheter, the treatment group was taught to perform Intermittent Self Dilatation by inserting a Classic Nelaton catheter (16 Fr) twice a week for six months.

ARM-II: NO DILATATION GROUP (CONTROL GROUP)

There was no further treatment needed in control group and patients were followed on regular basis.

\section{Follow-up and Outcome Measures}

Both the treatment and control groups were examined as outpatients at 1 month, 3 month and 6 month. The patients were asked about treatment problems, lower urinary tract syndrome (as per AUA) at each follow-up visit. Uroflowmetry measured urine flow, and a urine sample was taken for culture and sensitivity if signs of urinary tract infection were noted.

If a patient had no subjective symptoms of urethral stricture and if he produces a urine volume of at least $100 \mathrm{ml}$ on a non-flattened curve with a maximum flow of more than $15 \mathrm{ml} / \mathrm{s}$, he was considered to be stricture-free. If the flow was less than $10 \mathrm{ml} / \mathrm{sec}$ in repeated measurements, then the patient was admitted for urethrocystoscopy.

\section{Confirmation of Stricture}

On the result of urethrocystoscopy (free passage of the 20F scope to the bladder) a diagnosis of recurrence was determined. Thus, each patient was classified by objective methods at each follow-up as having a recurrence or being stricture-free.

\section{Dropouts}

Patients who did not produce a satisfactory flow but who did not want to undergo urethroscopy, those who were unable to come for follow up despite repeated requests and those who wanted to withdraw from the study were classified as 'dropouts'.

\section{Primary outcome Variable}

The main outcome of interest was the outcome of stricture at 6 months of follow up and was confirmed by, imaging urethrocystoscopy. Urethrocystoscopy was used as gold standard for presence/absence of a stricture. This outcome was created by a binary variable; Yes/No and the rate of stricture were compared between the two groups.

\section{Secondary outcome Variable}

1. Overall comfort (I was very much pleased with the result of biweekly ISD after the DVIU in last 6 months)

Satisfaction on 5 points LIKERT scale:

a. 1: strongly agree; 2 : agree; 3 : cannot say; 4 : do not agree; 5 : strongly disagree

2. Dysuria Yes/No

If yes, whether you need any medication

3. Episodes of UTI requiring antibiotics

\section{Statistical Analysis}

The data from case record formed on a structured proforma was entered in excel database. Patient's information was coded and patient's name was not entered. The statistical analysis was carried out by SPSS (Version 17).

Patient's data were analyzed by both Intentions to Treat (ITT) and per protocol. The baseline characteristics were expressed on number and percentage for categorized variable on mean \pm SD for continuous variable. Between the groups comparison of efficacy was assessed by chi square test and Mann Whitney $U$ test. A $P$ value of $<0.05$ was considered statistically significant.

\section{RESULTS}

Initially 42 urethral stricture patients were screened, of these 12 (28.57\%) were excluded, as they could 
not meet the inclusion criteria. Finally 30 patients were enrolled in the study and randomized in two groups: intermittent self-dilatation group and no dilatation group. Twenty-nine patients completed the six months study period. One patient in the control group came for follow up at the end of first month mountainous area he wanted to be excused from sixth month follow up. The age of patients enrolled in the study ranged from 19 years to 80 years. Majorities were in the age group of $48-58$ years. The mean \pm SD age, IPSS score, Uroflowmetry characteristics, Stricture size in the intermittent self-

Table 1. Pre Intervention characteristics of Intervention and Control group

\begin{tabular}{llccc}
\hline S.N. & \multicolumn{1}{c}{ Characteristics } & $\begin{array}{c}\text { ARM 1 } \\
\text { (Intervention) }\end{array}$ & ARM 2 (Control) & $\begin{array}{c}\text { P value } \\
\text { (using t test) }\end{array}$ \\
\hline 1 & Age & $41.73 \pm 15.43$ years & $48.33 \pm 13.85$ & 0.182 \\
& & & years & \\
2 & IPSS & $25.27 \pm 5.57$ & $22.53 \pm 5.35$ & 0.182 \\
3 & Uroflowmetry & $6.20 \pm 1.89$ & $5.73 \pm 1.94$ & 0.511 \\
4 & Stricture Size & $9.67 \pm 3.65 \mathrm{~mm}$ & $8.47 \pm 4.56 \mathrm{~mm}$ & 0.434 \\
\hline
\end{tabular}

Table 2. Pre Intervention characteristics of Intervention and Control group

\begin{tabular}{|c|c|c|c|c|c|c|}
\hline S.N. & Characteristics & & $\begin{array}{c}\text { ARM } \\
\text { (Intervention) } \\
n=\%\end{array}$ & $\begin{array}{c}\text { ARM } \\
\text { (Control) } \\
n=\%\end{array}$ & $\begin{array}{l}\text { Total } \\
\mathrm{n}=\%\end{array}$ & $\begin{array}{c}\text { P value } \\
\text { (Using Chi } \\
\text { sq) }\end{array}$ \\
\hline \multirow[t]{4}{*}{1} & Cause (aetiology) & Idiopathic & $5(55.5)$ & $4(44.5)$ & $9(100)$ & 0.878 \\
\hline & & Traumatic & $5(45.5)$ & $6(54.5)$ & $11(100)$ & \\
\hline & & latrogenic & $3(42.8)$ & $4(57.2)$ & $7(100)$ & \\
\hline & & Inflammatory & $2(66.7)$ & $1(33.3)$ & $3(100)$ & \\
\hline \multirow[t]{2}{*}{2} & Urine $\mathrm{C} / \mathrm{S}$ & Sterile & $13(56.5)$ & $10(43.5)$ & 23100) & 0.390 \\
\hline & & Non Sterile & $2(28.6)$ & $5(71.4)$ & $7(100)$ & \\
\hline \multirow[t]{2}{*}{3} & Suprapubic Catheter & Yes & $10(52.6)$ & $9(47.4)$ & 19(100) & 0.705 \\
\hline & $\begin{array}{l}\text { characteristics } \\
\text { (SPC) }\end{array}$ & No & $5(45.5)$ & $6(54.5)$ & $11(100)$ & \\
\hline \multirow[t]{2}{*}{4} & Pelvic fracture & Yes & $1(100.00)$ & $0(0)$ & $1(100)$ & N/A \\
\hline & & No & $14(48.3)$ & $15(51.7)$ & $29(100)$ & \\
\hline
\end{tabular}

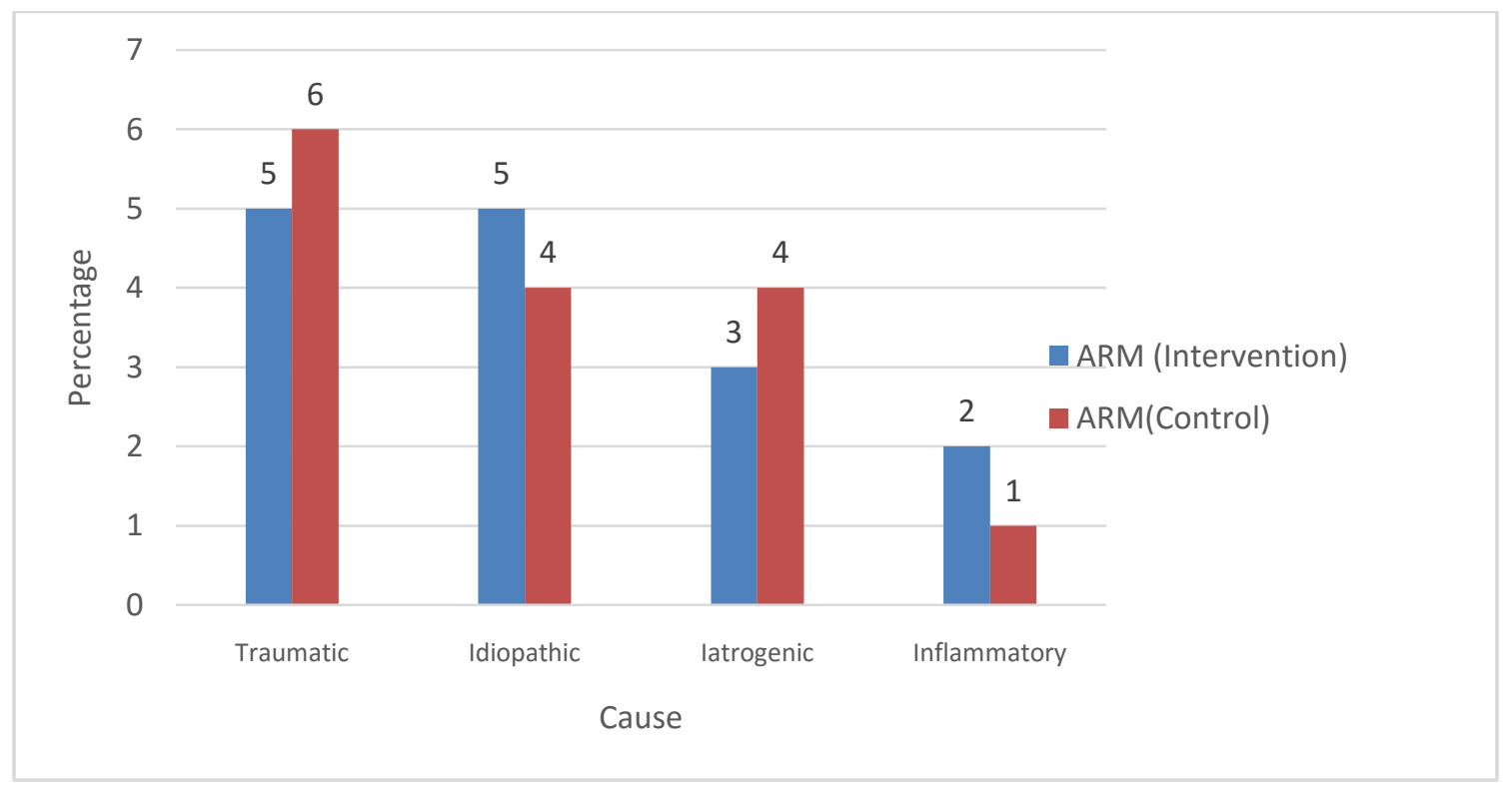

Fig.1. Aetiology of stricture

and third month, since the patient had no clinical issues till this time and also was from remote dilatation group and in the no dilation group was as shown in the table 1. 
Table 3. Comparison of Stricture at 6 months following Intermittent Self Dilatation in intervention and control groups per protocol

Group Stricture at 6 months

\begin{tabular}{lccc}
\cline { 2 - 4 } & Present & Absent & Total \\
& $\mathbf{n}(\%)$ & $\mathbf{n}(\%)$ & $\mathbf{n}(\%)$ \\
ARM I & $0(0)$ & 15 & 15 \\
(Intervention) & & $(100)$ & $(100)$ \\
ARM II & $3(21.4)$ & 11 & 14 \\
(Control) & & $(78.6)$ & $(100)$ \\
\hline
\end{tabular}

Aetiology, urine culture and other preinterventional characteristics

The most common aetiology for urethral stricture was found to be trauma. The aetiology of stricture in the two arms was not significantly different and comparable. The urine culture was sterile in majority of the cases in both the groups. Among the cases in which organisms were isolated, E.Coli was the most common organism. All the patients were treated for urinary tract infection before surgery and urine was sterile before Direct Visual Internal Urethrotomy. The details of the aetiology characteristics, urine culture characteristics, Suprapubic Catheter characteristics, and Pelvic Fracture characteristics is shown in table 2

Stricture at 6 months following Intermittent Self Dilatation in intervention and control groups as per protocol

In the intervention group $(n=15)$, none of the patients had stricture at six months whereas in control group, 3 out of $14(21.4 \%)$ had stricture at six months (table $3)$. One patient in the Control group followed up at the end of $1^{\text {st }}$ month and $3^{\text {rd }}$ month however he did not turn up for the follow up at the end of 6 months.

Stricture at 6 months following Intermittent Self Dilatation in intervention and control groups per Intention to treat

Table 5. Post Intervention Dysuria among the Intervention group

\begin{tabular}{cccc}
\hline Group & \multicolumn{3}{c}{ Dysuria } \\
\cline { 2 - 4 } & Present & Present & Present \\
& at 1 & at & at 6 \\
& month & 3month & month \\
& $(\%)$ & $(\%)$ & $(\%)$ \\
Intervention & $5(33.3)$ & $2(13.3)$ & $0(0)$ \\
\hline
\end{tabular}

Table 4. Comparison of Stricture at 6 months following Intermittent Self Dilatation in intervention and control groups per Intention to treat Group Stricture at 6 months

\begin{tabular}{ccc}
\hline Present & Absent & Total \\
$\mathbf{n}(\%)$ & $\mathbf{n}(\%)$ & $\mathbf{n}(\%)$ \\
$0(0)$ & $15(100)$ & 15 \\
& & $(100)$
\end{tabular}

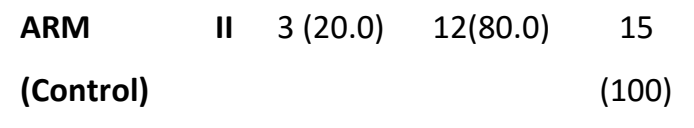

In the intervention group ( $n=15)$, none of the patients had stricture at six months whereas in control group, 3 out of $15(20 \%)$ had stricture at six months per intention to treat.

Post Intervention Dysuria among the Intervention Out of 15 patients in the intervention group, 5(33.3\%) experienced dysuria at 1 month, 2(13.3\%) at 3 months and none at the end of six months respectively (table 5).

Post Intervention Comparison of Urinary tract Infection among the Intervention and control groups

At 1 month, 5 out of $15(33.3 \%)$ in the intervention group and 4 out of $15(26.7 \%)$ in the control group had urinary tract infection respectively. At 3 months, 1 out of $15(6.7 \%)$ in the intervention group and 2 out of $15(13.3 \%)$ in the control group had urinary tract infection respectively (table 6). No one was presented with UTI at the 6 month.

Comparison of the Uroflowmetry findings of the Intervention and Control groups

The Qmax increased significantly in both the groups after intervention, from $6.20 \pm 1.89$ to $22.93 \pm$ 1.62 (around three times) in the intervention group and from $5.73 \pm 1.94$ to $17.86 \pm 9.25$ (around three times) the control group. However the pre/post intervention difference (Mean $\pm S D$ ) in Qmax scores between the intervention $(16.73 \pm 3.10)$ and the control group (12.36 \pm 8.63$)$ was not statistically significant.

Likert scale rating of Overall comfort of patients at 6 months following Intermittent Self Dilatation

On Likert scale rating of Overall comfort the patients were asked whether they were pleased with the result of biweekly ISD after the DVIU in the last 6 months, to that $4(26.7 \%)$ patients strongly agreed, $7(46.7 \%)$ patients agreed and $4(26.7 \%)$ patients could not say. 


\section{DISCUSSION}

Urethral stricture remains complicated surgical problem for mankind since ancient time and thus the treatment remains to evolve. In 1980s, the concept of intermittent self-dilatation (ISD) following DVIU took shape in order to decrease stricture recurrence. This is the first randomized controlled study of its type in Nepal to evaluate the usefulness of Intermittent Self Dilatation in prevention of recurrence in cases of stricture urethra following Direct Visual Internal Urethrotomy. Initially 42 urethral stricture patients were screened, of these 12 $(28.57 \%)$ were excluded, as they could not meet the inclusion criteria. Finally 30 patients were enrolled in the study and randomized in two groups: intermittent self-dilatation group and no dilatation group.

The majority of patients presenting with stricture urethra were in age group of 48.58 years (range 1980 years) in our study. The mean age in the intermittent self-dilatation group was 41.7 years and in the no dilatation group (control group) was 48 years. This mean age is similar to that of reported in the study by O.B. Shittu ${ }^{9}$ as being 42 years and by Palminteri et $\mathrm{al}^{2}$ who showed the mean age of urethral stricture as 45.1 years.

International Prostate Symptom Score (IPSS) is a modality of clinical outcome measure. Lemma ${ }^{10}$ in his study validated the use of IPSS in urethral stricture patients. In our study the mean IPSS before intervention in control group was 22 and in intervention group was 25 . The IPSS showed significant decrease in score after intervention in both the groups. This shows the utility of IPSS in urethral stricture.

Stricture recurrence has been shown to be directly proportional to the stricture length. In a study done by Jezior ${ }^{11}$ he concluded that Direct Visual Internal Urethrotomy is best utilized for short strictures less than $1.5 \mathrm{~cm}$ that involves bulbar or pendulous urethra. In this study Direct Visual Internal Urethrotomy had long term success rate of $74 \%$. The length of stricture in this study is taken as less than $1.5 \mathrm{~cm}$. Steenkamp et $\mathrm{al}^{12}$ also showed that strictures $<1 \mathrm{~cm}$ and $1-2 \mathrm{~cm}$ in length have similar recurrence rates approx. $40 \%$ at 24 months.

The mean stricture length in the intervention group and control group was $9.7 \mathrm{~mm}$ and $8.5 \mathrm{~mm}$ respectively in our study. The stricture length for intervention in our study is comparable with the study done by Jezior ${ }^{11}$. The length of urethral stricture was less than $1.5 \mathrm{~cm}$ in our all cases.

The outcome assessment after Direct Visual Internal Urethrotomy is done with urethral calibration with a catheter, uroflowmetry, flexible cystourethroscopy,
American Urological Association symptom index and urethrographic studies. There is no uniformly accepted method of follow up. Uroflowmetry is noninvasive, cheap and acceptable method by patients. So uroflowmetry was used as a tool for assessing the outcome of the procedure in our study.

Study done by Pansadoro ${ }^{13}$ also showed that stricture recurrence could be diagnosed on the basis of uroflowmetry in $84 \%$ of cases. Another study done by Heyns and Marais ${ }^{14}$ showed that uroflowmetry could save $34 \%$ of patients from future invasive testing such as urethrography.

Keeping with above in this study uroflowmetry was taken as a guide to follow the patients post-surgery to evaluate in the improvement of urinary flow. In both the groups there was remarkable improvement; the flow increased from 6 to $23 \mathrm{~m} / \mathrm{sec}$ in intervention group and from 5 to $18 \mathrm{ml} / \mathrm{sec}$ in control group with uroflowmetry.

This study shows a positive correlation of uroflowmetry and the degree of urethral obstruction. Trauma represents a very significant etiology of urethral stricture disease. Different mechanisms of trauma result in urethral strictures with straddle injury being the most common as studied by Palminteri ${ }^{2}$. Other mechanisms of traumatic injury include pelvic fracture-related urethral injury (PFUI) and iatrogenic injury secondary to instrumentation. Straddle injuries typically occur during work, bicycle riding, and sports.

The leading cause for stricture urethra was traumatic (36.7\%) in our study, followed by Idiopathic, latrogenic and inflammatory. This is similar to the study done by Stein et al . He did two studies. In one study done in US and Italy the most common cause for stricture was idiopathic at $(41.3 \%)$ followed by latrogenic at (35\%). In another study by Stein et $\mathrm{al}^{5}$, done in India the most common cause was traumatic at (36\%). My study also shows a preponderance of traumatic causes for stricture urethra. Only one case of traumatic stricture urethra was associated with pelvic fracture. This can be attributed to rapid urbanization and increase in road traffic incidents.

Urinary infections are extremely frequent in male urethral stenosis. It has high morbidity with complications. In our study the urine culture was sterile in majority of cases preoperatively, $13 \%$ of patients in both the groups were diagnosed with urinary tract infection. The most common organism isolated was Escherichia Coli. Romero ${ }^{15}$ evaluated its real incidence, clinical and microbiological aspects, complications and morbidity, in a group of 175 male patients presenting with urethral stenosis evaluated 
Table 6. Post Intervention Comparison of Urinary tract Infection among the Intervention and control groups Group Urinary tract

Infection

\begin{tabular}{ccc}
\hline Present & Present & Present \\
at 1 & at & at 6 \\
month & 3month & month
\end{tabular}

(\%) (\%)

ARM I

$$
5 \text { (33.3) }
$$

(Intervention)

ARM II $\quad 4(26.7) \quad 2(13.3) \quad 0(0)$

(Control)

during a period of 11 year. He pointed out that the high incidence of urinary infections affects $36 \%$ of patients. It was caused in $90 \%$ of cases by a single bacterium, $44 \%$ of which were due to Escherichia Coli. This difference is probably due to wide availability of over the counter medication in our country. We also assessed for dysuria in the intervention group. In the group who had undergone DVIU and Intermittent Self Dilatation, dysuria decreased from $33 \%$ at one month to none at the end of six month. The contributing factor for dysuria in the initial period can be attributed to improper technique and perception, which gradually improved with time.

In our study recurrence of stricture was not present in the group with Intermittent Self Dilatation at 6 months period, however in the control group 3 patient developed strictures and 1 patient was lost to follow up.
Jackson $^{16}$ (Cochrane review) reviewed on Intermittent Self Dilatation for urethral stricture disease in males concluded that men with urethral stricture who perform intermittent self-dilatation may have less chance of their urethral stricture coming back than men with a urethral stricture who do not perform intermittent self-dilatation.

In comparison to the other study the follow up period in our study was small. In a study done by Lauritzen ${ }^{17}$ they showed that median time until recurrences were 732 days in Intermittent Self Dilatation group and 167 days in non-Intermittent Self Dilatation group.

In another study by Harriss et $a^{18}{ }^{18}$ they divided patients into 2 groups the $1^{\text {st }}$ group did Intermittent low-friction self-catheterization twice

weekly for 6 months and the $2^{\text {nd }}$ group performed Intermittent low-friction self-catheterization for 36 months. In the group who stopped at 6 months $40 \%$ of patients developed the recurrence whereas in the other group only $14 \%$ developed recurrence. Ten patients in the $2^{\text {nd }}$ group who continued with permanent intermittent low-friction selfcatheterization remained stricture free till the end of the study period. Another study by Roosen ${ }^{19}$ concluded that Clean Intermittent Self Catheterization seems to be a promising preventive measure against recurrence of urethral stricture. However just like our study they also took a follow up period of 6 month.

Another study by Bodker ${ }^{7}$ concluded that for the treatment of urethral stricture Clean Intermittent Self Catheterization following Optical Internal Urethrotomy should be continued for long duration, possibly permanently.

Based on these findings we found that most of the

Table 7. Comparison of the Uroflowmetry findings of the Intervention and Control groups

\begin{tabular}{|c|c|c|c|c|c|}
\hline & $\begin{array}{l}\text { Baseline } \\
\text { Mean } \pm S D \\
\text { (Median) }\end{array}$ & $\begin{array}{l}\text { At } 6 \text { month } \\
\text { follow up } \\
\text { Mean } \pm S D \\
\text { (Median) }\end{array}$ & $\begin{array}{l}\text { Wilcoxon } \\
\text { Signed } \\
\text { Rank Test }\end{array}$ & $\begin{array}{l}\text { Pre/Post } \\
\text { Intervention } \\
\text { Difference } \\
\text { Mean } \pm S D \\
\text { (Median) }\end{array}$ & $\begin{array}{l}\text { P Value } \\
\text { (Mann } \\
\text { Whitney U } \\
\text { Test) }\end{array}$ \\
\hline $\begin{array}{l}\text { Arml } \\
\text { (Intervention } \\
\text { group) }\end{array}$ & $\begin{array}{l}6.20 \pm 1.89 \\
(6.00)\end{array}$ & $\begin{array}{l}22.93 \pm 1.62 \\
(23.00)\end{array}$ & 0.001 & $\begin{array}{l}16.73 \pm 3.10 \\
(17.00)\end{array}$ & 0.219 \\
\hline $\begin{array}{l}\text { Armll } \\
\text { (Control group) }\end{array}$ & $\begin{array}{l}5.73 \pm 1.94 \\
(5.50)\end{array}$ & $\begin{array}{l}17.86 \pm 9.25 \\
(21.50)\end{array}$ & 0.002 & $\begin{array}{l}12.36 \pm 8.63 \\
(14.50)\end{array}$ & \\
\hline
\end{tabular}


Table 8. Likert scale rating of Overall comfort of patients at 6 months following Intermittent Self Dilatation Group Overall Comfort (Very Much Pleased)

\begin{tabular}{cccc}
\hline $\begin{array}{c}\text { Strongly Agree, } \mathbf{n} \\
(\%)\end{array}$ & Agree $\mathbf{n}(\%)$ & $\begin{array}{c}\text { Can not Say, } \\
\mathbf{n}(\%)\end{array}$ & Total $\mathbf{n}(\%)$ \\
$4(26.7)$ & $7(46.7)$ & $4(26.7)$ & $15(100)$
\end{tabular}

Intervention group

$4(26.7)$

$4(26.7)$

$15(100)$

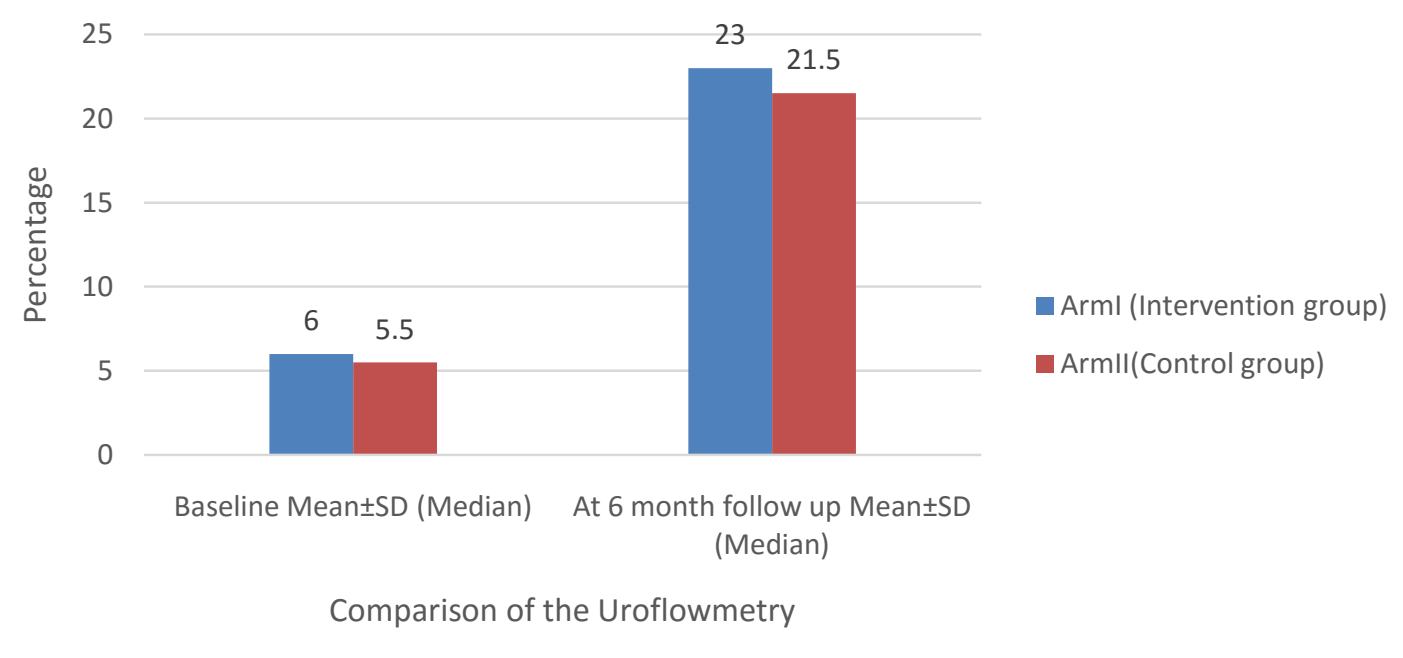

Fig.2. Comparison of the Uroflowmetry in both groups

recurrence in the Intermittent Self Dilatation group occurs later than the 6 month evaluation period. However the effect of Intermittent Self Dilatation till it is continued seems to be helpful in preventing the recurrence as none of the patients in the Intermittent Self Dilatation group developed recurrence in our study.

We used the Likert scale for the purpose of gazing overall comfort of patients with Intermittent Self Dilatation and evaluated the measures in improvement of overall wellbeing during Intermittent Self Dilatation. We found that $26.7 \%$ of the present study populations were very much comfortable,

$46.7 \%$ were comfortable and $26.7 \%$ were unable to comment

\section{CONCLUSION}

Our study showed that recurrence of stricture was markedly decreased over the six month of follow up period in the intermittent self-dilatation group. Although the follow up period was only six month there was a clear trend towards improvement in the intervention group. Overall comfort in the intermittent self-dilatation group as measured by Likert scale showed that most of the patients did not find the procedure to be uncomfortable. Dysuria in intervention group showed a trend towards disappearance as the time passed. None of the patients had dysuria at the end of six months. The number of urinary tract infection in both the intervention and control group was comparable at the first month of follow up and there was also a trend towards decrease in frequency of urinary tract infection as time progressed. Pre-operative voiding symptom (International Prostate Symptom Score) and uroflowmetry determination may be considered as a baseline evaluation to facilitate objective assessment of intervention outcomes and monitoring over time.

\section{REFERENCES}

1.Wein AJ, Kavoussi LR, Novick AC. Campbell-Walsh Urology Tenth Edition, Saunders 2011;1:967.

2. Palminteri $E$, Berdondini $E$, Verze $P$, De Nunzio $C$, Vitarelli A, Carmignani L. Contemporary Urethral Stricture Characteristics in the Developed World. Urology; 2013 Jan;81(1):191-7. Available from: http://dx.doi.org/10.1016/i.urology.2012.08.06

3. Lumen N, Hoebeke P, Willemsen P, De Troyer B, Pieters R, Oosterlinck W. Etiology of Urethral Stricture Disease in the 21st Century. The Journal of Urology ; 2009 Sep;182(3):983-7. Available from: http://dx.doi.org/10.1016/i.juro.2009.05.023 
4.Kashefi C, Messer K, Barden R, Sexton C, Parsons JK. Incidence and Prevention of latrogenic Urethral Injuries. The Journal of Urology; 2008 Jun;179(6):2254-8. Available from: http://dx.doi.org/10.1016/j.juro.2008.01.108

5.Stein DM, Thum DJ, Barbagli G, Kulkarni S, Sansalone S, Pardeshi A, et al. A geographic analysis of male urethral stricture aetiology and location. BJU ; 2012 Dec 18;112(6):830-4. Available from: http://dx.doi.org/10.1111/j.1464-410x.2012.11600.x

6.Kjaergaard B, Walter S, Bartholin J, Andersen JT, $\mathrm{N} ø$ hr S, Beck $\mathrm{H}$, et al. Prevention of urethral stricture recurrence using clean intermittent selfcatheterization. British Journall; 1994 Jun;73(6):6925. Available from: http://dx.doi.org/10.1111/i.1464410x.1994.tb07558.x

7.Bodker A, Ostri P, Rye-Andersen J, Edvardssen L, Struckmann J. Treatment of recurrent urethral stricture by internal urethrotomy and intermittent self-catheterisation: A controlled study of a new therapy. J Urol 1992;148:308-10.

8. Matanhelia SS, Salaman R, John A, Mathews PN. A prospective randomized study of self dilatation in the management of urethral strictures. $J R$ CollSurgEdinb 1995;40:295-7.

9. Shittu OB. Internal optical urethrotomy in the management of urethral strictures inNigerians:Technique and outcome. African Journal of Urology 2001; 7(2):62-5.

10. Lemma $B E$, Taye $M$, Hawando $T$. International prostate symptom score as a clinical outcome measure for Ethiopian patients with urethral stricture. Ethiop Med J 2001;24:277-81.

11. Jezior J. Management of Bulbous Urethral Stricture. AUA update series. Eastern Viginia Medical School,1993.

12. Steenkamp JW, Heyns CF, DeKock MI. Internal urethrotomy versus dilatation as treatment for male urethral strictures:A prospective, randomized comparison. J Urol 1997;157:98-101.

13.Pansadoro V, Emiliozzi P. Internal Urethrotomy in the Management of Anterior Urethral Strictures. The Journal of Urology; 1996 Jul;73-5. Available from: http://dx.doi.org/10.1097/00005392-199607000$\underline{00020}$

14. Heyns CF, Marais DC. Prospective Evaluation of the American Urological Association Symptom Index and Peak Urinary Flow Rate for the Followup of Men With Known Urethral Stricture Disease. The Journal of Urology ; 2002 Nov;2051-4. Available from: http://dx.doi.org/10.1097/00005392-200211000$\underline{00036}$

15. Romero PP, Mira LA. Urinary infection and urethral stenosis in males. ActasUrolEsp 1990;14(6):401-6.

16.Jackson MJ, Veeratterapillay R, Harding CK, Dorkin TJ. Intermittent self-dilatation for urethral stricture disease in males. Cochrane database of systemic reviews; 2014 Dec 19; Available from: http://dx.doi.org/10.1002/14651858.cd010258.pub2

17.Lauritzen M, Greis G, Sandberg A, Wedren H, Öjdeby G, Henningsohn L. Intermittent self-dilatation after internal urethrotomy for primary urethral strictures: A case-control study. Scandinavian Journal of Urology and Nephrology ; 2009 Jan;43(3):220-5. Available from: http://dx.doi.org/10.1080/00365590902835593

18.Harriss DR, Beckingham IJ, Lemberger RJ, Lawrence WT. Long-term results of intermittent lowfriction self-catheterization in patients with recurrent urethral strictures. British Journal of Urology; 1994 Dec;74(6):790-2. Available from: http://dx.doi.org/10.1111/i.1464-

410x.1994.tb07127.x

19.Roosen JU. Self-Catheterization after Urethrotomy. Urologia International; 1993;50(2):902.Availablefrom:

http://dx.doi.org/10.1159/000282459 